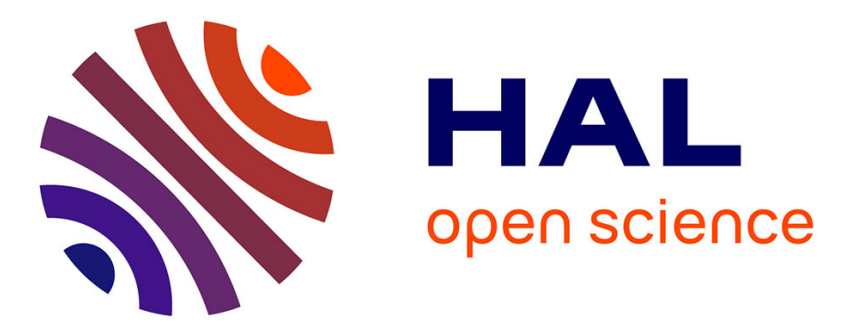

\title{
S-Parameter Measurements of High-Temperature Superconducting and Normal Conducting Microwave Circuits at Cryogenic Temperatures
}

\author{
J. Lauwers, S. Zhgoon, Nour Eddine Bourzgui, B. Nauwelaers, J. Carru, A. \\ van de Capelle
}

\section{To cite this version:}

J. Lauwers, S. Zhgoon, Nour Eddine Bourzgui, B. Nauwelaers, J. Carru, et al.. S-Parameter Measurements of High-Temperature Superconducting and Normal Conducting Microwave Circuits at Cryogenic Temperatures. Journal de Physique IV Proceedings, 1996, 06 (C3), pp.C3-397-C3-401. 10.1051/.jp4:1996360 . jpa-00254278

\section{HAL Id: jpa-00254278 https://hal.science/jpa-00254278}

Submitted on 1 Jan 1996

HAL is a multi-disciplinary open access archive for the deposit and dissemination of scientific research documents, whether they are published or not. The documents may come from teaching and research institutions in France or abroad, or from public or private research centers.
L'archive ouverte pluridisciplinaire HAL, est destinée au dépôt et à la diffusion de documents scientifiques de niveau recherche, publiés ou non, émanant des établissements d'enseignement et de recherche français ou étrangers, des laboratoires publics ou privés. 


\title{
$S$-Parameter Measurements of High-Temperature Superconducting and Normal Conducting Microwave Circuits at Cryogenic Temperatures
}

\author{
J. Lauwers, S. Zhgoon*, N. Bourzgui**, B. Nauwelaers, J.C. Carru** and A. Van de Capelle \\ K.U. Leuven, Departement Electrotechniek, Afdeling ESAT/TELEMIC, Kard. Mercierlaan 94, \\ 3001 Heverlee, Belgium \\ * Moscow Power Engineering Institute (MPEI), Dept. of Radioengineering Fundamentals, \\ Krasnokazarmennaja 14, 105835 Moscow, E250, Russia \\ **Institut d'Électronique et de Microélectronique du Nord (IEMN), Département Hyperfréquences et \\ Semiconducteurs, BP 69, Cité Scientifique, Avenue Poincaré, 59652 Villeneuve d'Ascq, France
}

\begin{abstract}
A fixture is presented that accepts both normal and superconducting microstrip structures for S-parameter measurements. The use of small replaceable inserts and a compression contact for the strip makes the fixture especially suited for rapid prototype testing of microstrip circuits. The technique is explained and measurements at room temperature and at low temperatures are demonstrated.
\end{abstract}

\section{INTRODUCTION}

In this paper, a microstrip fixture for microwave measurements at cryogenic temperatures is presented. The technique was developed in order to allow rapid prototype testing of normal metal and high- $T_{c}$ superconducting circuits. The mounting technique allows to use the fixture at and below liquid nitrogen temperatures, while high quality electrical contacts are guaranteed without using soldering or gluing techniques. Rapid and easy replacement of test samples results and is an important advantage of the procedure.

Measurements of both conventional MICs and superconducting circuits, down to $20 \mathrm{~K}$, are presented.

\section{MEASUREMENT FIXTURE AND TECHNIQUE}

The fixture, illustrated in Figure 1, is used in conjunction with replaceable inserts on which the samples are mounted. Since fast cooling down of the fixture is of great interest when measuring multiple samples, a low thermal capacity is required. This is achieved by a construction of the fixture in aluminum and keeping the parts as small and as thin as possible without compromising the mechanical strength. The insert itself however, is made of brass or copper for reasons explained below.

\subsection{Main principle}

Figure 2 illustrates the main principle of the microstrip fixture.

The cross section shows the microstrip circuit mounted on the replaceable insert, which in turn, is screwed onto the fixture. The central pins of the coaxial connectors are pressed onto the circuit by a $U$ shaped PTFE part and a small spring. In this way we avoid soldering of the connector pins. This is very delicate because of the risk of peeling of the narrow strip or damaging the high $T_{c}$ superconducting film, which can result from the heating of the superconductor.

To avoid unwanted resonances in the cavity formed by the cryostat, the circuit is packaged in a small metalic can. This cover also serves as a holder for the spring and PTFE part and can be adjusted to accommodate for different substrate widths. 


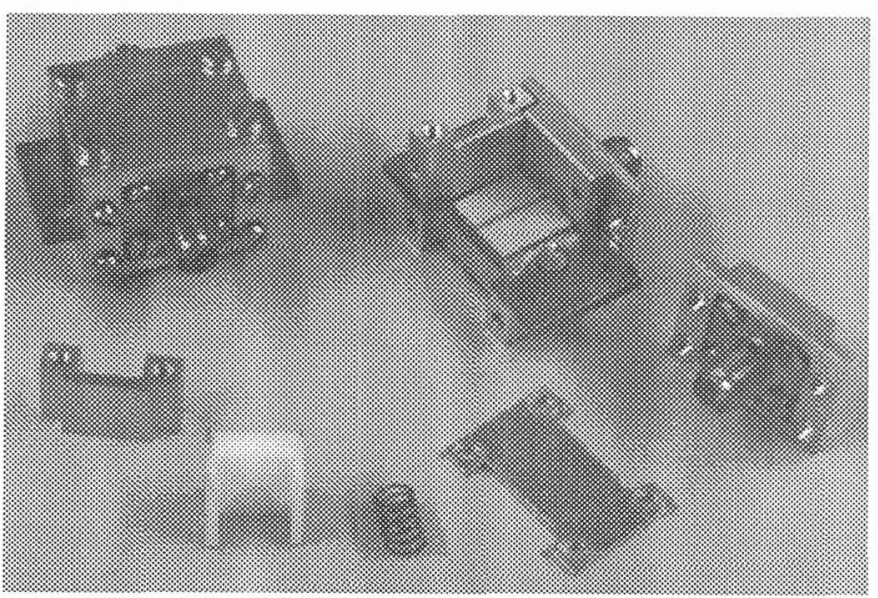

Figure 1: Photograph of the fixture

\subsection{Mounting of the circuit on the replaceable insert}

Testing a circuit starts with mounting the circuit on an insert. This can be done in two ways, depending on the existence of a ground plane on the substrate itself.

In the first case, when a ground plane exists on the backside of the substrate, the circuit is soldered with this backplane to an insert. To allow this soldering, the insert is made of brass. Because excessive heat causes deoxygenation of high- $T_{c}$ superconducting thin films, which results in increased surface resistivity, we have to limit the soldering temperature to $150{ }^{\circ} \mathrm{C}$. For this reason, we use Woods alloy, a soldering alloy melting at $70^{\circ} \mathrm{C}$. Mounting the circuit on the insert in this way, ensures a good and reliable electrical and thermal contact between the circuit's ground plane and the fixture, even at very low operating temperatures.

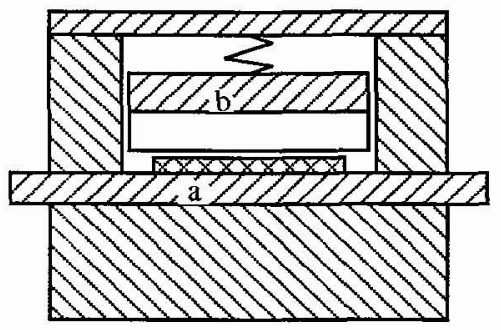

Figure 2: Cross section of the fixture, (a) replaceable insert, (b) U-shaped PTFE part

In the second case, when there is no ground plane on the substrate, the sample is just put on the insert and will be pressed onto it, together with the central connector pins. To limit the losses in this groundplane, it is necessary to use an insert with a high conductivity and a smooth surface. For these reasons, copper is preferred and the surface should be polished. This second mounting method can also be used in combination with a groundplane on the substrate.

\subsection{Mounting of the connectors}

After mounting the sample, the insert is screwed to the fixture. The SMA-connectors, that can slide up and down to accommodate to different substrate heights, are screwed in a position where the connector pin is resting on the microstrip line. Next, the U-shaped PTFE part is inserted and is pressed to the 
connector pins by the small spring. Another heating step of the superconducting thin film is avoided and the risk for damaging the film in this way, is limited.

\subsection{Advantages of the followed procedure}

Using a separate insert for each circuit together with the compression contact allows fast and easy replacement of the device under test without damaging the fixture and the circuit. In this way we need only one complex test fixture and as many cheap inserts as there are samples to be measured in the case of soldering. In the case of pressing the circuit to the insert, just one polished insert is necessary. Soldered devices are left on the insert and stored in that way. Remeasurements of the same circuit can be performed without another time consuming mounting procedure.

\section{MEASUREMENTS}

\subsection{Classical $50 \Omega$ microstrip transmission line}

Measurements of a $10 \mathrm{~mm}$ long microstrip line on a $0.635 \mathrm{~mm}$ thick alumina substrate are shown in Figure 3 . The line was designed to be $50 \Omega$ at room temperature. Measurements were performed with a HP $8510 \mathrm{C}$ network analyser and an in-house built cryostat. A lower temperature of $65 \mathrm{~K}$ is reached by using cheap and readily available liquid nitrogen.

The calibration of the network analyser is performed at room temperature with a coaxial calibration kit. So, the influence of the coaxial to microstrip transition is included in the measurements.
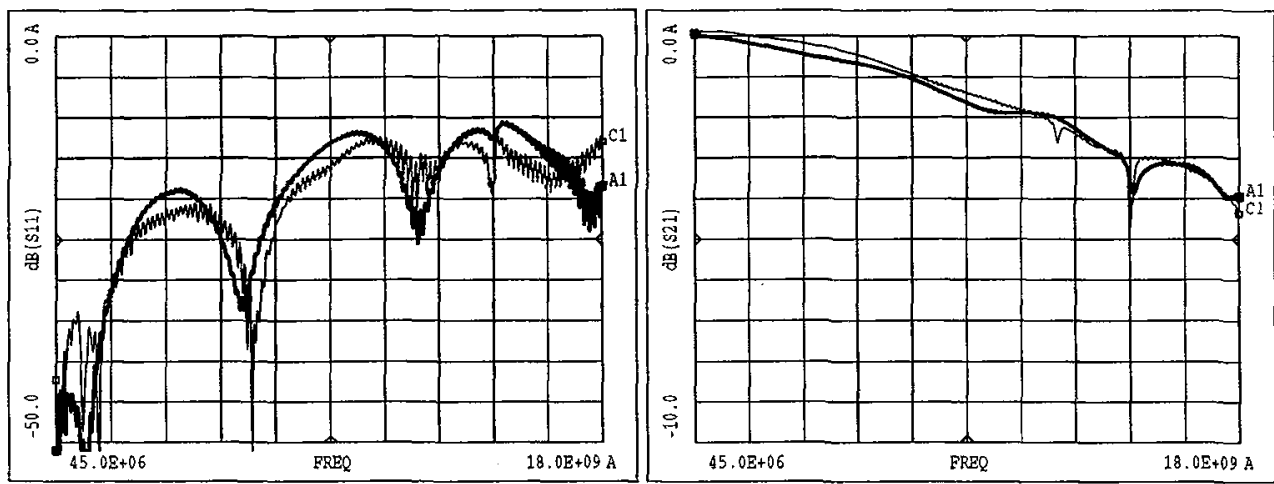

Figure 3: Response of a $50 \Omega$ microstrip line, thick line: $297 \mathrm{~K}$, thin line: $77 \mathrm{~K}$

At room temperature, the return loss is below $-11 \mathrm{~dB}$ up to $14 \mathrm{GHz}$ and the insertion loss is lower than $1.7 \mathrm{~dB}$ at $9 \mathrm{GHz}$. Starting at $14.5 \mathrm{GHz}$ resonances show up. This are resonances in the small cavity, which holds the PTFE part and the spring.

At $77 \mathrm{~K}$, we obtain reflection levels better than $-12 \mathrm{~dB}$ up to $14 \mathrm{GHz}$. Transmission parameters are slightly above $0 \mathrm{~dB}$ at lower frequencies. This is caused by errors due to cooling of the measurement cables which were not included in the calibration. This influence on the S-parameters can be measured and extracted from the results.

\subsection{Superconducting microstrip resonator with superconducting groundplane}

The fixture was also successfully used in the measurements of superconducting linear microstrip resonators down to a temperature of $20 \mathrm{~K}$. For these measurements a closed cycle cryorefrigerator and a HP $8510 \mathrm{~B}$ network analyser, at IEMN were used. Figure 4 shows the response of a linear microstrip resonator at $20 \mathrm{~K}$. The circuit is made of $\mathrm{a} \approx 0.5 \mu \mathrm{m}$ thick $\mathrm{YBa}_{2} \mathrm{Cu}_{3} \mathrm{O}_{7}$ superconducting film on a $0.5 \mathrm{~mm}$ thick $\mathrm{MgO}$ substrate. In order to realise better contact, the contact pads are covered with a $\approx 0.5 \mu \mathrm{m} \mathrm{Ag}$ 
layer. The groundplane is a similar $\mathrm{YBa}_{2} \mathrm{Cu}_{3} \mathrm{O}_{7}$ superconducting film, also covered by an $\mathrm{Ag}$ layer and is soldered to a brass insert.

The unloaded quality factor and the resonant frequency versus temperature are shown in Figure 5.

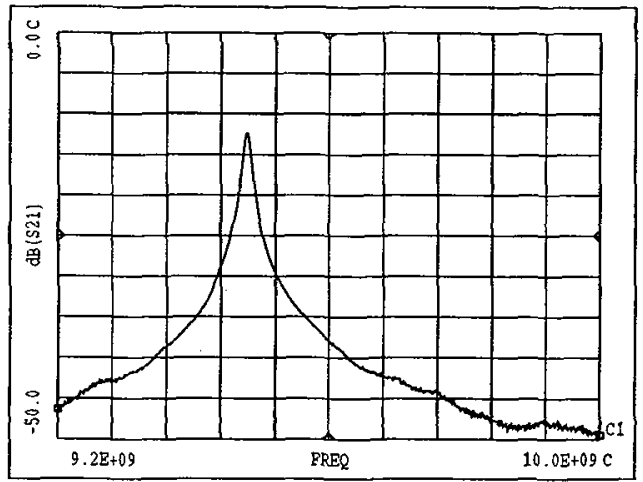

Figure 4: Measurement of a superconducting linear microstrip resonator at $20 \mathrm{~K}$

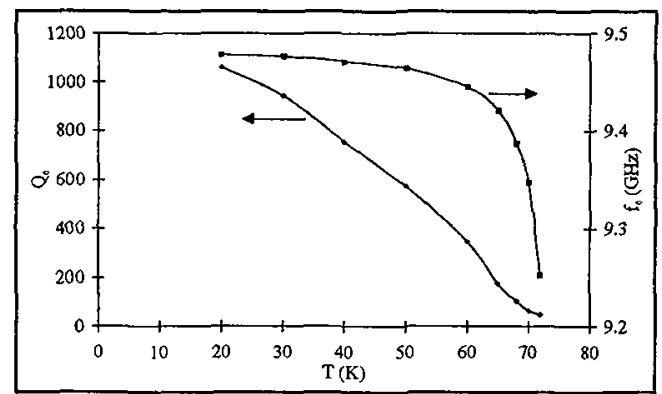

Figure 5: Unloaded $Q$ and resonant frequency versus temperature

\subsection{Superconducting microstrip resonator with brass groundplane}

The described technique can also be used when there is no back plane metallisation on the substrate. The insert is then used as a ground plane for the microstrip circuit. The response of the resonator shown in Figure 6, at $65 \mathrm{~K}$, is given in Figure 7. The circuit is made of an $\mathrm{YBa}_{2} \mathrm{Cu}_{3} \mathrm{O}_{7}$ superconducting film on a sapphire substrate. A brass insert was used as groundplane. A copper insert, giving lower loss and higher $Q$ values, will be tested in the near future.

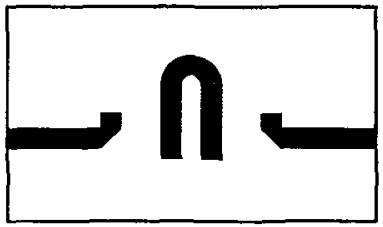

Figure 6: Microstrip resonator 


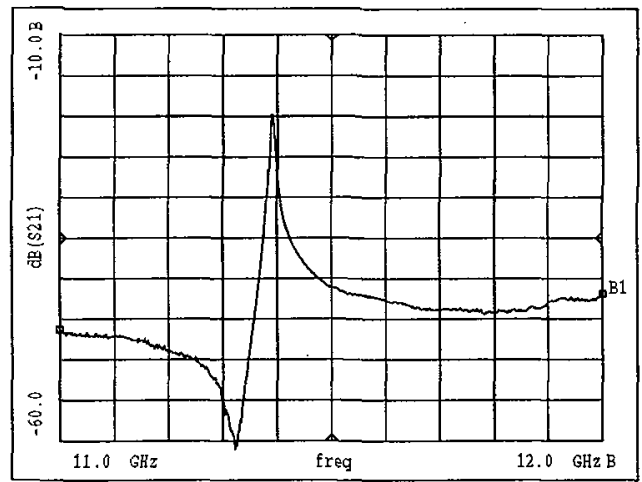

Figure 7: Response of the resonator of Figure 6 at $65 \mathrm{~K}$

\section{CONCLUSIONS}

A fixture that accepts both normal and superconducting microstrip structures for $S$ parameter measurements, was developed. The use of small replaceable inserts and a compression contact for the strip makes the fixture especially suitable for rapid prototype testing of microstrip circuits.

Measurements of both normal conducting and superconducting circuits show that the fixture can be used at and below liquid nitrogen temperatures, while good electrical contacts are guaranteed.

To further increase the accuracy of the measurements, the fixture can be used in combination with a LRL calibration method, which can be performed at any measurement temperature.

\section{Acknowledgement}

The authors would like to thank Patrick Neirynck and Pieter Panis for their help with the experimental work and Rudi Casteels, for the precise fabrication of the test fixtures. We would also like to thank the ASP-CSP division of IMEC for the preparation of the alumina test samples.

\section{References}

[1] J. W. Smukk, M. G. Stubbs and J. S. Wight: "Enhanced microwave characterisation technique for cryogenic temperatures", IEE Electronics Letters, 1990, Vol. 26, No. 25, pp. 2127-2129.

[2] J. W. Smukk, M. G. Stubbs and J. S. Wight: "Vector measurements of microwave devices at cryogenic temperatures", IEEE MTT-S Digest, 1989, pp. 1195-1198.

[3] A. Madjar, A. Breithard, U. Meirav and A. Messica: "A miniature microwave measurement fixture for operation up to $40 \mathrm{GHz}$ and at temperatures approaching absolute zero", IEEE MTT-S Digest, 1994, pp. 1053-1056.

[4] Z-Y. Shen: "High-Temperature Superconducting Microwave Circuits", Artech House, BostonLondon, 1994. 